\title{
Una visión integradora de la historia Crónica de la visita de Raúl Porras Barrenechea a Chile
}

Recibido: 16/11/2017

Aprobado: 01/12/2017

\author{
Ricardo Pinto-Bazurco Mendoza \\ Universidad Nacional Mayor de San Marcos \\ < rpintobazurcom@unmsm.edu.pe >
}

\begin{abstract}
RESUMEN
La historia como herramienta de integración y conciliación resulta eficaz para el desarrollo de los pueblos y más aún cuando sus historias han atravesado vaivenes. En tal sentido la presencia de Raúl Porras Barrenechea en Santiago de Chile, durante la celebración del simposio en homenaje al centenario del nacimiento de José Toribio Medina, constituye un hecho precursor y visionario. Pues su aporte a la heurística de la historiografía chilena, con documentación inédita, y su muestra de gratitud y reconocimiento al trabajo de quien él consideró uno de los más importantes historiadores constituyó el eje principal de su discurso convirtiendo, de esta manera, la Historia en un elemento integrador entre el Perú y Chile. Esta comunidad «espiritual e histórica», presente en la vida de ambos pueblos fue lo que llevó a Medina, dice Porras, a mirar el Perú como a una «entidad histórica fraterna» y que Porras reafirma al considerar una simbiosis entre ambos países cuya historia se nutre y enriquece, constantemente. Hecho que se reafirma, históricamente, con personajes como Pedro de Ońa o Bernardo O’Higgins y que Raúl Porras Barrenechea delineó, magistralmente, en esos días de octubre de 1952.
\end{abstract}

PALABRAS CLAVE: Historia - Integración - Porras - Perú - Chile.

\section{An integrated vision of history Chronicle of the visit of Raúl Porras Barrenechea to Chile}

\begin{abstract}
History as a tool of integration and conciliation is effective for the development of the people and even more so when their stories have gone through swings. In this sense, the presence of Raúl Porras Barrenechea in Santiago, Chile, during the celebration of the symposium in homage to the centenary of the birth of José Toribio Medina, is a precursor and visionary event. For his contribution to the heuristic of Chilean historiography, with unpublished documentation, and his show of gratitude and recognition to the work of who he considered one of the most important historians constituted the main axis of his discourse, converting, in this way, the History in an integrating element between Peru and Chile. This «spiritual and historical» community, present in the life of both peoples, was what led Medina, says Porras, to see Peru as a «historical fraternal entity» and that Porras reaffirms when considering a symbiosis between both countries whose history it nourishes and enriches, constantly. A fact that is reaffirmed, historically, with characters such as Pedro de Oña or Bernardo O’Higgins and that Raúl Porras Barrenechea delineated, masterfully, in those days of October 1952.
\end{abstract}

KEYWORDS: History - Integration - Porras - Perú - Chile. 
a presencia de Raúl Porras Barrenechea ${ }^{1}$ en Santiago de Chile, durante la celebración del simposio en homenaje al centenario del nacimiento de José Toribio Medina Zavala², fue una de las más reconocidas actuaciones académicas de este destacado intelectual sanmarquino fuera de nuestras fronteras. Pues su aporte a la heurística chilena, con documentación inédita, fue una muestra de gratitud y reconocimiento al trabajo de quien él consideró uno de los más importantes historiadores de su época y que además calificó como uno de sus maestros y figura de inspiración académica.

Uno de los principales ejes temáticos que Porras ofreció en las diferentes disertaciones fue la relación de Medina con el Perú convirtiendo, de esta manera, la Historia en un elemento integrador entre el Perú y Chile. Su discurso se sostenía sobre la idea de que esta comunidad "espiritual e histórica», presente en la vida de ambos pueblos llevó a Medina a mirar el Perú como a una "entidad histórica fraterna» y que Porras reafirma al considerar una simbiosis entre ambos países cuya historia se nutre y enriquece, constantemente. Hecho que se reafirma, históricamente, con personajes como Pedro de Ońa o Bernardo O’Higgins y que Raúl Porras Barrenechea delineó, magistralmente. Este último detalle es el leitmotiv de esta líneas conmemorativas que nos evocan al jueves 16 de octubre de 1952, cuando en la Sala Barros Arana de la Biblioteca Nacional de Santiago de Chile, el doctor Raúl Porras Barrenechea participó como parte de la delegación que envió el gobierno peruano al Homenaje por el Centenario del nacimiento de José Toribio Medina.

La delegación fue presidida por el embajador del Perú en Santiago de Chile, el doctor Alberto Ulloa, quien además fue acompañado por el doctor José Jiménez Borja y el ingeniero Cristóbal de Losada y Puga (Fénix 1952) quienes compatieron reflexiones, con otros especialistas internacionales, en torno a los aportes que dejó el insigne biblógrafo chileno.

Fue historiador, jurista, crítico literario, diplomático y maestro. Insigne peruanista cuyos aportes y reflexiones muestran una gran capacidad en el manejo de la heurística y el análisis crítico a través de los diferentes periodos de nuestra historia.

2 (Santiago, 21 de octubre de 1852-11 de diciembre de 1930). Fue nombre se encuentra estrechamente vinculado al patrimonio cultural de Chile. Su aporte se tradujo en una abundante recopilación de obras, fuentes y documentos para la historia y la literatura colonial hispanoamericana. En www.memoriachilena.cl

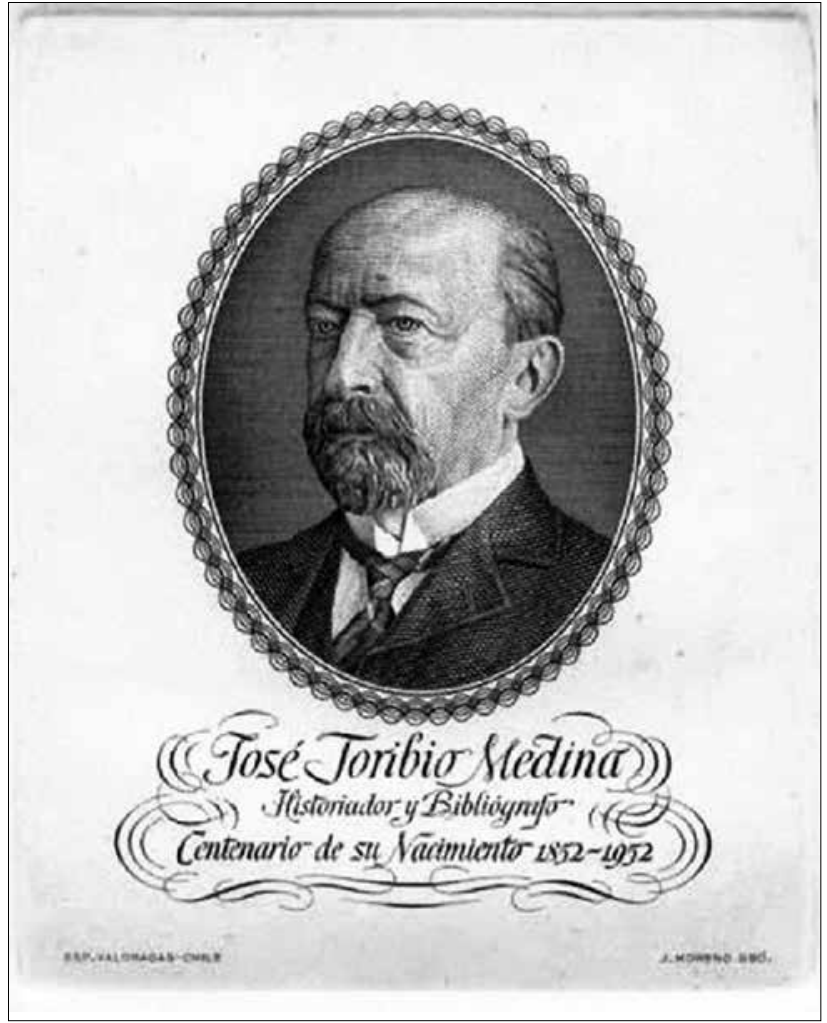

Programa alusivo al homenaje a José Toribio Medina Colección BNCH, 1952

Cabe mencionar que el doctor Porras, no sólo ejerció su papel como miembro de la delegación ad hoc, también se desempeñó como representante oficial de la "Academia Antártica», como él acostumbraba a llamar a la Universidad de San Marcos de Lima, y del rector Pedro Dulanto ${ }^{3}$.

El discurso, en primer término, hizo presente el saludo corporativo de la «vieja casa de estudios generales de América» (Porras 1952: 491) a las autoridades y cuerpo académico chileno para luego dar paso a la disertación que inició de la siguiente manera:

«Hemos venido los representantes de la Universidad de San Marcos de Lima, a la que iban los estudiantes de Chile en los siglos XVII y XVIII, en una nave de tarda lona, como las que traían en los días virreinales «el situado de Chile» o la «leva de Chile» para la guerra indiana (...) llevaba el nombre de Américo Vespucio» (Porras 1952: 492). abogado, bibliógrafo, investigador, historiador y coleccionista. Su
Aquella oportunidad, el doctor Porras, presentó dos trabajos que posteriormente intituló Medina y su 3 La representación de Porras fue designada por encargo del Consejo
Universitario. 


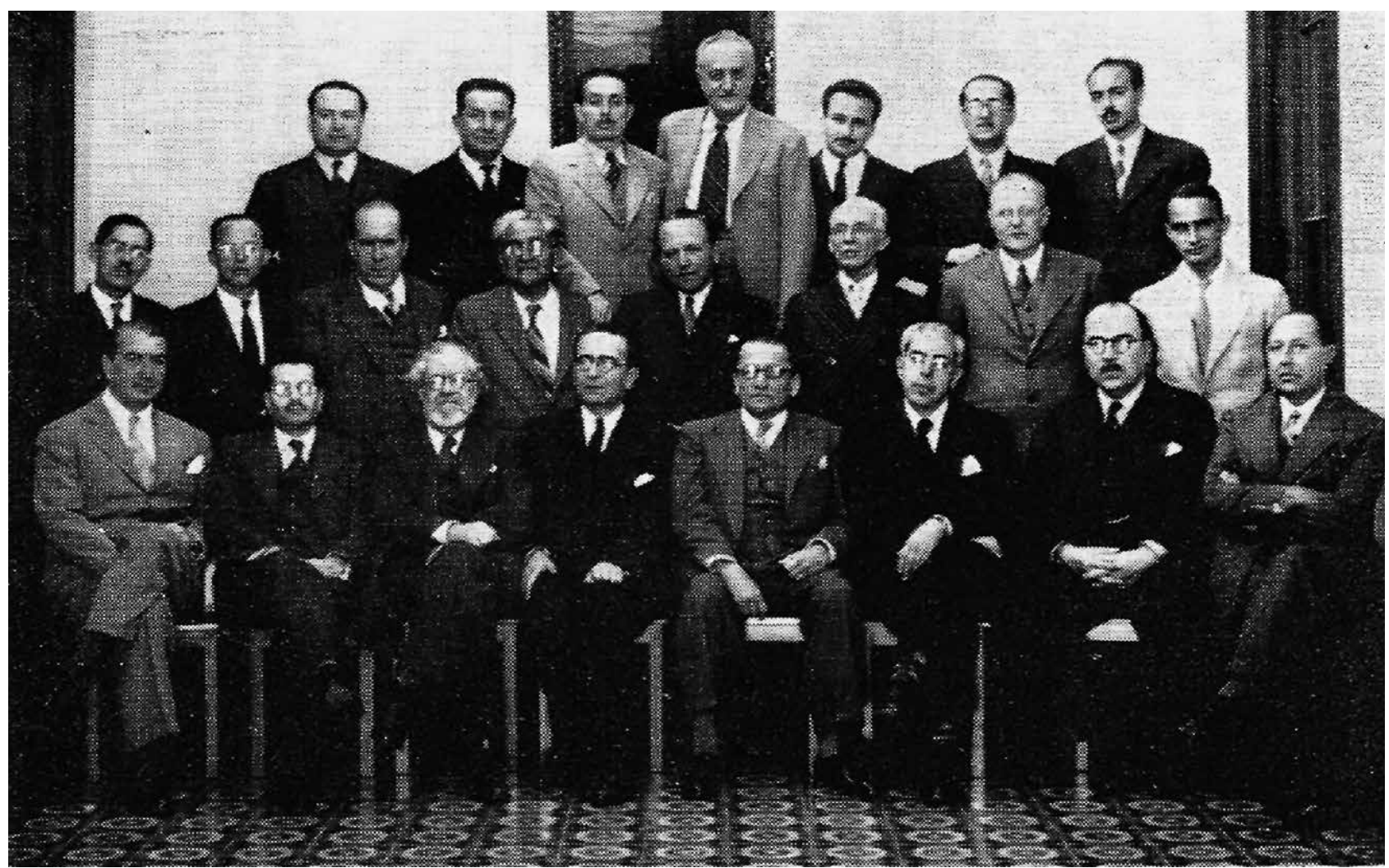

Claustro reformista de la Facultad de Letras y Pedagogía de la Universidad de San Marcos de 1945. Fila I (izq. a der., sentados): Drs. Felipe Cosio del Pomar, Pedro Dulanto, José Gálvez Barrenechea, Luis E. Valcárcel, Carlos Monge, Luis Alberto Sánchez, Roberto Mac Lean Estenós y José Jiménez Borja. Fila II (izq. a der., parados): Drs. César Góngora Perea, Javier Pulgar Vidal, Oswaldo Hercelles, Julio C. Tello, Raúl Porras Barrenechea, Manuel Beltroy, Teodosio Cabada y Luis Felipe Alarco. Fila III (izq. a der., parados): Drs. Nicandro Pareja, Ántero Peralta, Luis Fabio Xammar, Roberto Reich, Carlos Daniel Valcárcel, Julio A. Chiriboga y Walter Peñaloza. (Fuente: Acervo Pinto-Bazurco).

contribución a la historia de peruana y otro llamado Nuevos datos sobre la vida del poeta chileno Pedro de Oña. Al respecto, se tenía poca claridad sobre los datos biográficos del primer poeta chileno, quien estudió e imprimió su auspiciosa obra, El Arauco Domado (1596), en La Ciudad de los Reyes. Este personaje fue de sumo interés para don Raúl del cual logró recuperar vital información para la construcción de su biografía. Algunos hechos debidamente escudriñados en los archivos fueron que en Lima, hacia 1598, contrajo nupcias con doña Ana Farfán de los Godos, hija del fundador de Piura, con quien tuvo más de cinco hijos. Otros hechos radican que debido a su actividad poética obtuvo corregimientos, además fue funcionario del Tribunal del Santo Oficio y el dato que tuvo una confirmación biográfica inequívoca, no antes mencionada, fue que Pedro de Oña ofició como poeta, corregidor y justicia mayor de la provincia de Calca y Lares, en los alrededores del Cusco, entre 1630-1635. Esto sin olvidar que tuvo una importante vinculación con la Universidad de San Marcos como lo testifican los poemas de hipérbole gongórica ${ }^{4}$ y el primer diseño, libre, del escudo 5 sanmarquino ambos publicados en las Constituciones de 1602.

\section{Obsesión por la heurística}

Porras no dejó pasar la oportunidad para demostrar su gran capacidad en el manejo de la heurística al mencionar la figura de Alonso de Ercilla, autor de la Araucana (1569), quien también transitó por la

4 «Poema: A La Florentissima Vniversidad de Los Reyes. Dedicado Al glorioso evangelista, S. Marcos que tiene como symbolo al León y acrecentada por el Leon de España, nuestro muy Catholico Rey Phelipo Tercero. El menor hijo de ella Pedro de Ońa» (Constituciones y Ordenanzas de la Universidad, y Studio general de la Ciudad de los Reyes del Piru 1602: 21).

5 Sobre la participación de Oña en su diseño, Miguel Maticorena realizó un acertado apunte al respecto: «() Incorrecto la cara de un león alado (El ángel: Mateo, El buey: Lucas, El águila: Juan.) que aparece en el primer escudo impreso de San Marcos. Dibujada en la edición de las constituciones de 1581, editadas en Lima en 1602. Licencia que se tomaron el impresor italiano Antonio Ricardo y el poeta Pedro de Oña» (Maticorena 2000: 41). 


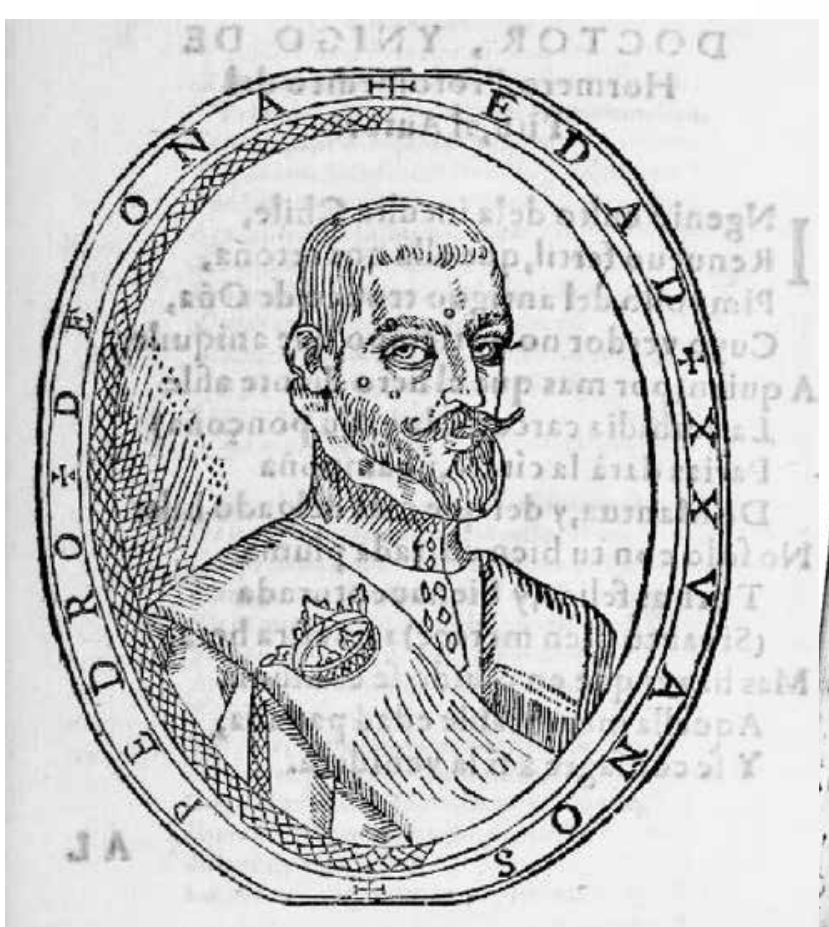

Pedro de Oña (con la beca del Colegio Real de San Felipe y San Marcos)

y su poema a la Universidad de San Marcos

Constituciones y Ordenanzas de la Universidad, y Studio general de la Ciudad de los Reyes del Piru, 1602

Ciudad de los Reyes en viaje a Chile lo cual le sirvió de inspiración como refiere en su famosa obra: "Costa a costa y a veces engolfado llegué al Callao de Lima celebrado» (Porras 1952: 493). Su evocación intelectual prosiguió por los derroteros de los siglos XVII y XVIII, cuando refirió que en una carta dirigida al rey Felipe V, consignada en enero de 1714, el Cabildo de Santiago denunció que «La Universidad Real de San Marcos de Lima es la única del reino de Chile» (Porras 1952: 494) y que a oponión de la autoridad eclesiástica si existiése una Universidad en esos lares no saldrían los jóvenes de ese reino hacia Lima (Porras, 1952).

\section{El abuelo y O'Higgins}

Su viaje en el tiempo por los recodos del antiguo régimen permitió al público oyente recalar en épocas de las guerras de independencia al evocar la figura del limeño Juan de Egaña, quien a modo de fraterna retroalimentación, fue a Chile para «escribir la primera constitución política de Chile y marcar los derroteros de su vida jurídica y constitucional» (Porras 1952:

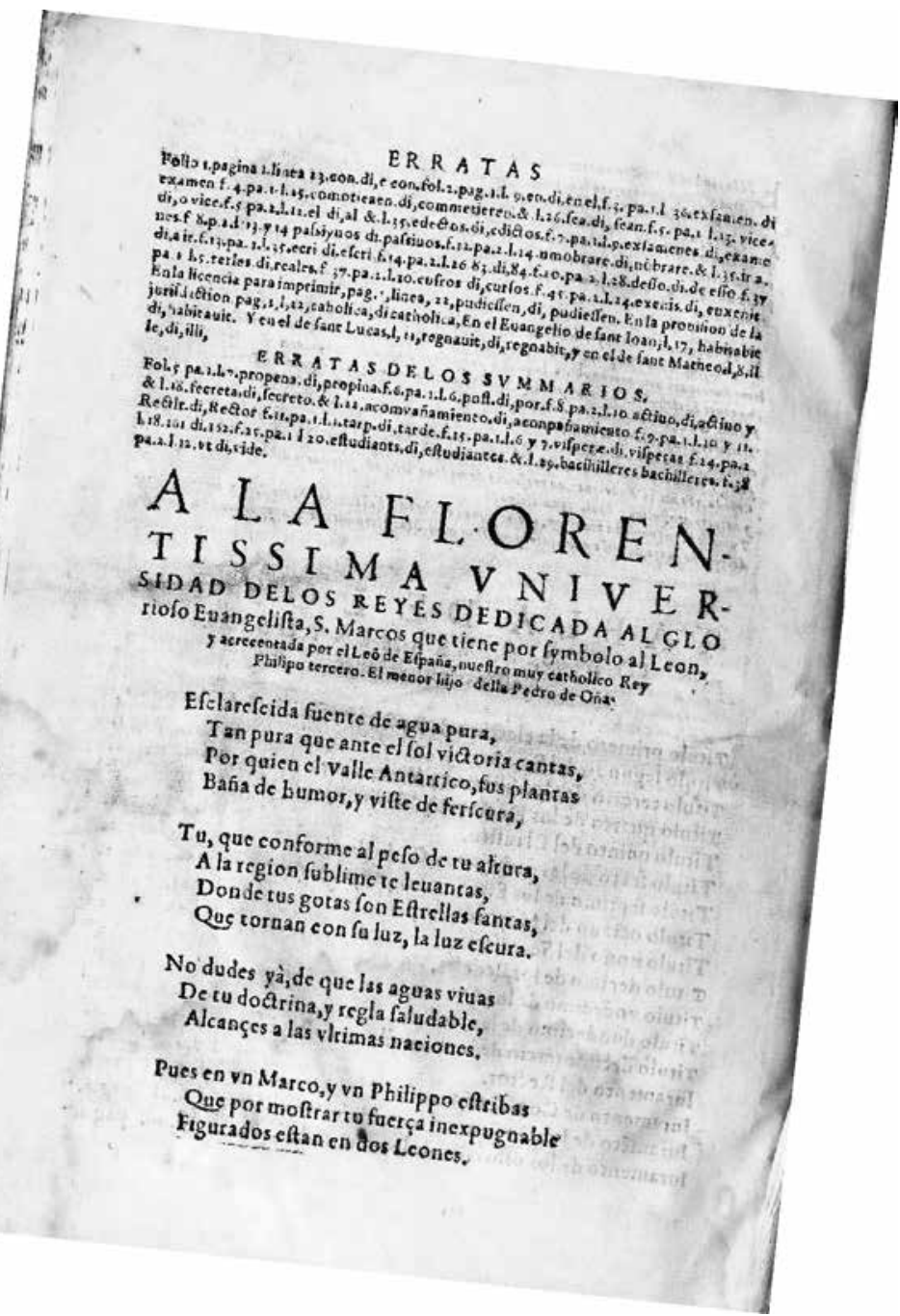

494). A su turno, y haciendo alarde de sus dotes de gran orador, su ejercicio evocador lo llevó a la otra figura central de su disertación: Bernardo O'Higgins al que calificó como «el más noble símbolo de la amistad peruana-chilena de todos los tiempos» (Porras 1952: 495). Personaje histórico del que tuvo una especial evocación pues el prócer se encontró vinculado a una de sus ramas familiares de manera muy especial, su abuelo materno. Cuando en tiempos que don José Antonio Barrenechea y Morales ejercía el cargo de Ministro de Relaciones Exteriores ${ }^{6}$ del Perú, a éste le tocó devolver las cenizas del precursor chileno a su tierra en 1868 (Porras 1929). En aquella oportunidad, el Canciller

6 (Lima, 24 de abril de 1829 - Lima, 20 de febrero de 1889). Fue llamado por primera vez a ocupar el Ministerio de Relaciones Exteriores en el mes de mayo de 1867, un año después del combate del Callao, desempeñando la cartera por el término de un mes (mayo 4 a junio 3) y volviéndola a ocupar bajo el mismo Gobierno de Prado, desde el mes de septiembre de 1867 al mes de enero de 1868, en que cayó dicho gobierno. En el siguiente periodo de Balta fue ministro por un año consecutivo (4 de agosto de 1868 a octubre 23 de 1869) (Porras 1929: XXIII). 
Barrenechea refirió en su discurso de orden, ante el Almirante Blanco Encalada, lo siguiente:

«Acabáis de recibir las cenizas del Capitán General Presidente de Chile, Gran Mariscal del Perú D. Bernardo O'Higgins (...) Decid a vuestro país que, al entregarle estos restos, cumplimos con el deber sagrado; pero que guardaremos eternamente el recuerdo del grande hombre, que no sólo trabajó por la independencia de su Patria, sino que envió la gloriosa expedición que debía iniciar la independencia de la nuestra (...) Vuestro Capitán General nos pertenecía, pero era ante todo vuestro. Por eso os lo devolvemos. Sin embargo esas cenizas os dirán que estaban naturalizadas en el Perú (...) En el poder, en la proscripción y en la tumba sirviendo a la misma causa: a la gran causa de la unión americana (...) él ha vivido y muerto en el seno de los amigos de su patria» (Porras 1929: 570-571).

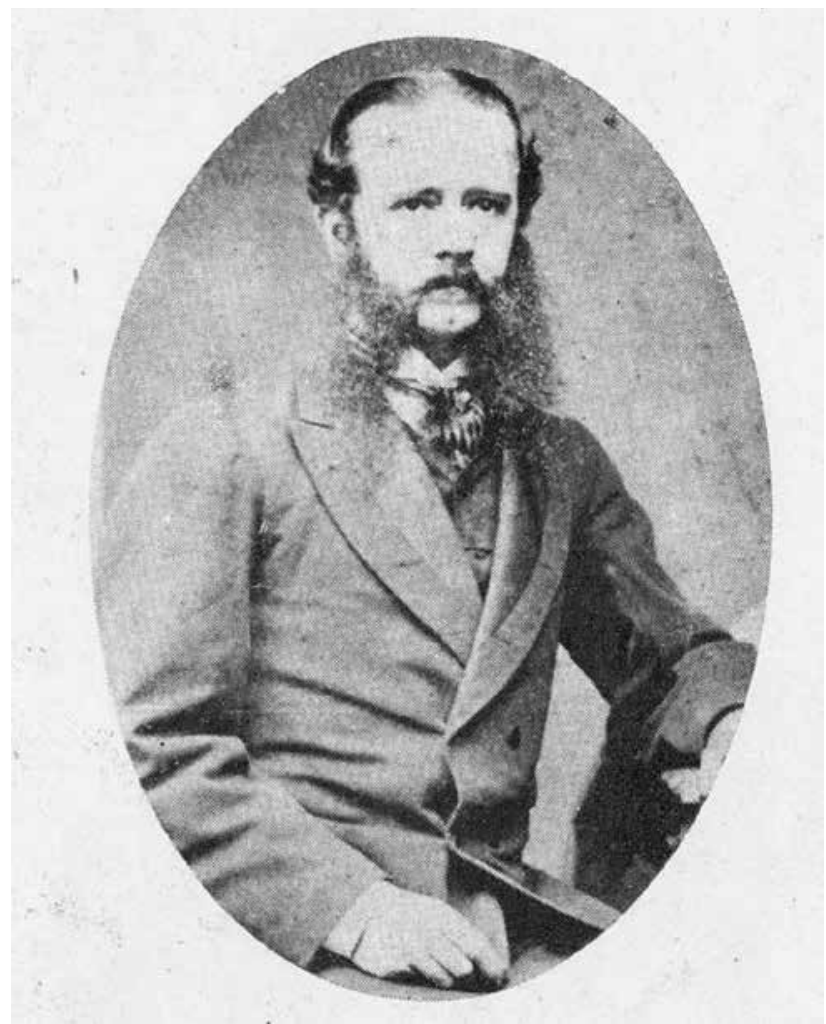

José Antonio Barrenechea y Morales como Canciller de la República Casa-museo IRPB

Al mismo tiempo, don Raúl, evocó un grato recuerdo de juventud que compartió con el público; cuando en 1928, en momentos de arduo debate internacional y de sensibilidad patriótica ${ }^{7}$ entre Perú

7 En 1925, Porras había sido miembro de la comisión peruana delimitadora para el caso de Tarata. Gracias a su sustento histórico y y Chile, Medina pasó por el puerto del Callao a bordo de una nave sajona llevando consigo dos publicaciones: la Bibliografía de las lenguas quechua y aimará y "las Cartas de Valdivia» hacia el Congreso de Americanistas de Nueva York. Cuenta Porras que acudió junto a otros, a la sazón, jóvenes aprendices de historia, al puerto con la finalidad de conocer y estrechar la mano del ya legendario autor de La Imprenta de Lima y de la Historia de la Inquisición limeña. Norte que consiguieron con creces pues se llevaron una autógrafa del sabio y la "conciencia de un deber espiritual cumplido" (Porras 1953). El impacto que generó este encuentro, entre el Sabio y la joven pléyade, fue tan profundo que Porras refirió en relación a ello: "desde entonces, en charlas y en dedicatorias de folletos primicios aquellos tres principiantes que éramos Luis Alberto Sánchez, Jorge Guillermo Leguía y yo, nos llamábamos mutuamente (...) los «José-toribios» (Porras 1952: 493). Luego, el doctor Porras, hizo una revelación al mencionar:

«Y tiempo después, cuando Sánchez y Leguía fueron notables investigadores del pasado peruano, Sánchez fue el primero y el único de nosotros que alcanzó a recibir el espaldarazo de Medina, que fue una rectificación de este (...) Y una cita de Medina, aunque fuera adversa, era una consagración» (Porras 1952: 493).

Fino sarcasmo, a modo de sainete propio de la «generación anatoliana» a la que don Raúl decía pertenecer, que le dio algo de jocosidad a su disertación.

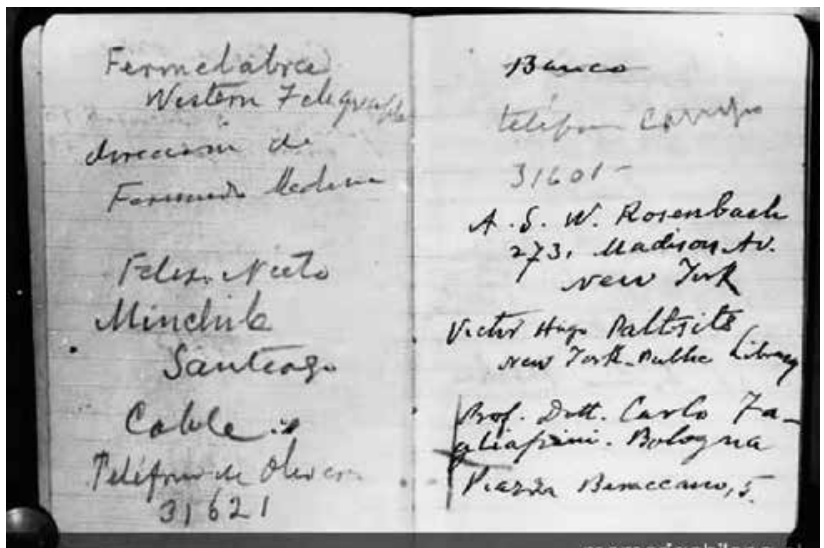

Libreta de apuntes del último viaje de José Toribio Medina a Estados Unidos y Europa en 1928

Colección BNCH

gestiones se logró el regreso de la provincia de Tarata al seno patrio. Hasta 1929 se vivió una tensa calma que culminó con el regreso definitivo de Tacna al Perú. 


\section{Nuevos aportes a la historia de Chile}

Las reminiscencias históricas mencionadas en su sugerente panegírico de eximio conversador no sólo quedaron ahí pues realizó un generoso aporte a la heurística chilena con la entrega, aquella tarde, de documentos inéditos como:

- Carta de obligación de Diego de Almagro al presbítero Bartolomé de Segovia, otorgada en «el valle de Coquimbo, provincia de Chile» del 5 de mayo de 1536. Que resalta por ser el primer y quizá único documento fechado del viaje a Almagro a Chile.

- Testamento, codicilo y amoneda de Rodrigo Horgoñez, 1545.

- Pedro de Valdivia, conquistador de Chile, obsequia a dońa Francisca Pizarro y Yupanqui, hija del conquistador del Peru, don Francisco Pizarro, una vajilla de oro en recuerdo y gratitud de los servicios que debía al marques, 1548.

- Carta de don pedro Valdivia a doña Isabel Guillen. Cuzco, 1548.

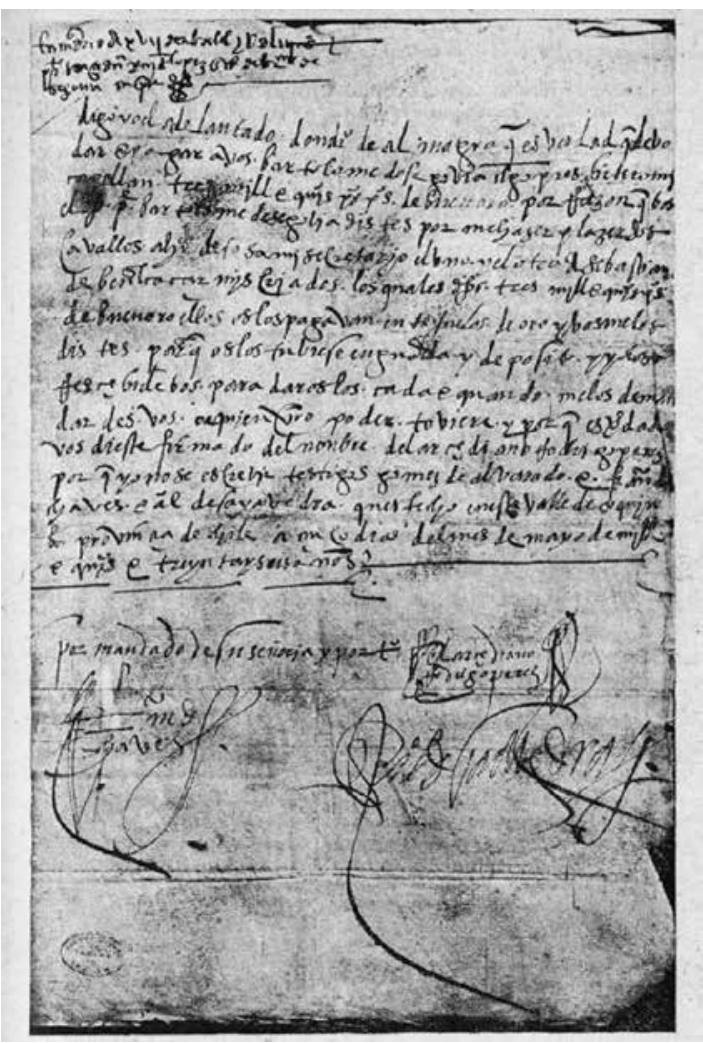

Primer documento fechado en la conquista de Chile. Carta de obligación de Diego de Almagro al presbítero Bartolomé de Segovia, otorgada en «el valle de Coquimbo, provincia de chile» (5 de mayo de 1536)

\section{Gratitud al maestro}

Esta fue la forma como Raúl Porras Barrenechea rindió tributo al trabajo, en señal de gratitud y reconocimiento, de quien él consideró uno de los más importantes historiadores de su época y que, además, calificó como uno de sus maestros y figura de inspiración académica al nombrarlo como el «alumbrador de la historia indohispánica y creador de una nueva mayéutica en la sabiduría del libro». Para Porras, inter alia, esta relación peruano-chilena se reafirma, históricamente, no solo con el vínculo con los personajes antes mencionados, y otros más, sino que parte desde tiempos prehispánicos lo cual contribuyó a formar la trama de la cultura chilena. En esta relación se mezclan, dijo:

«viejo hilos de oro de los mantos de Paracas, idolillos de piedra y cántaros en los que brilla en reflejos geométricos la luz del trópico, toponimias quechuas que todavía claman su origen cuzqueño en la línea del ferrocarril de Valparaíso a Santiago y oleadas culturales en las que viajan el maíz y las llamas simbólicas del Incario» (Porras 1952: 492).

De esta manera se genera una comunidad espiritual e histórica, la cual no solo se limitó al ámbito de las letras también incluyó la esfera comercial, presente en la vida de ambos pueblos que llevó a Medina a mirar el Perú, y Lima dentro de las tradiciones fecundas del pasado, como a una capital del espíritu en el continente antártico (meridional, sur), en el transcurso de toda su obra e identificarla como una entidad histórica fraterna y que Porras reafirma al considerar una simbiosis entre ambos países cuya historia se nutre y enriquece, constantemente, al estar unida indisolublemente desde el pasado más remoto convirtiendo, de esta manera, la Historia en un elemento integrador entre el Perú y Chile.

\section{Cobertura mediática internacional y nacional}

La descollante, y conciliadora, actuación de don Raúl fue reconocida y celebrada por unánime acuerdo entre las diferentes delegaciones participantes por lo que su figura fue catalogada como la personalidad más significativa del torneo «medinense», tal y como refirieron los principales diarios santiagueños como: el Mercurio, la Razón, el Ilustrado, entre otros.

Aquí unos ejemplos: 


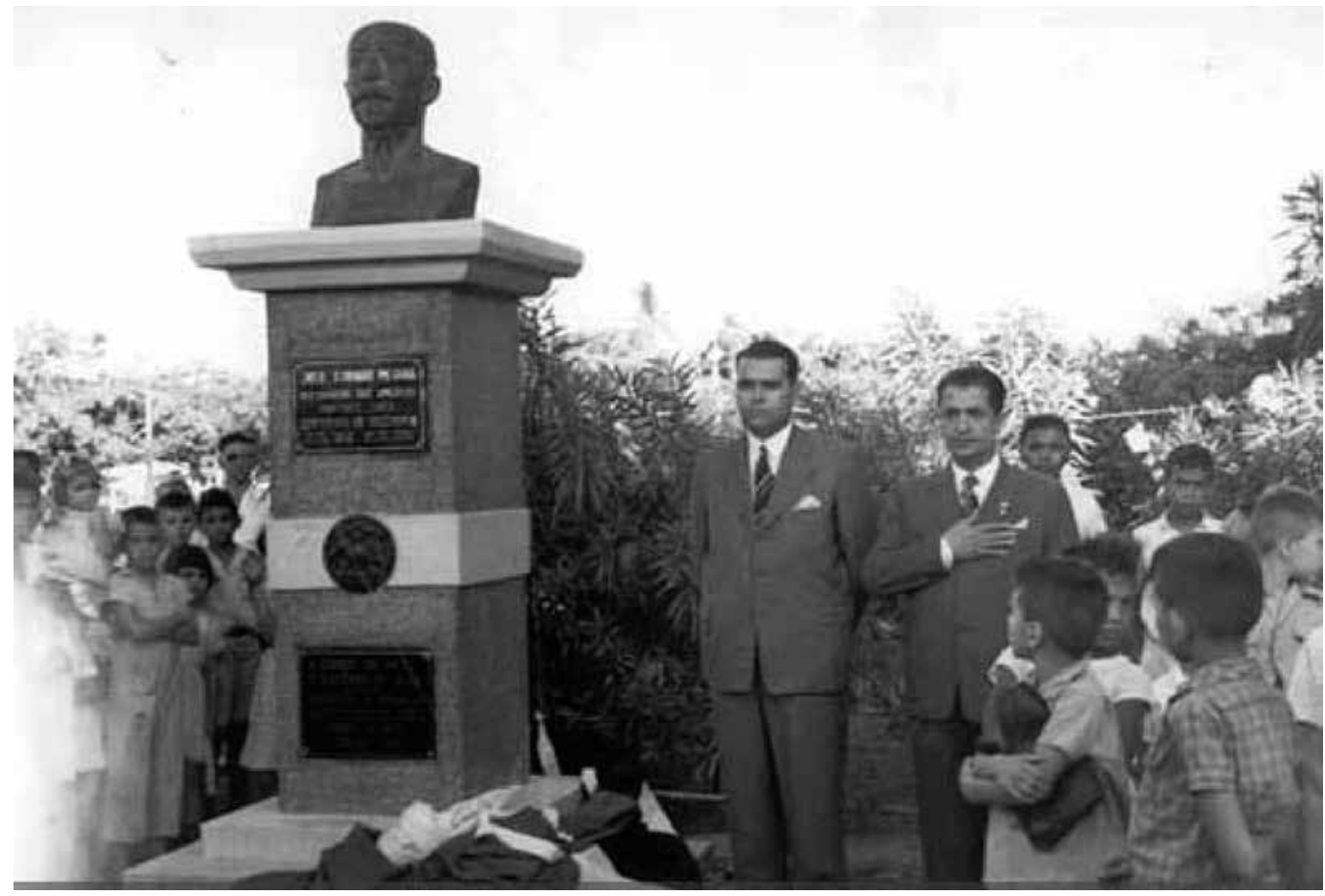

Romería a la Tumba de José Toribio Medina (colección BNCH - 1952) «entre los homenajes rendidos a don José Toribio Medina, la oración pronunciada el jueves por Raúl Porras Barrenechea quedará como bella y magistral pieza oratoria. Analizó el conferenciante los valiosos aportes del polígrafo al conocimiento de la historia peruana. $\mathrm{Y}$ en su palabra emocionada y fervorosa logró unir las elegancias de la erudición con lo primoroso y fluido del estilo. ¡Qué riqueza de significativos pormenores y qué fuerza sugerente definidora brotaba de los adjetivos maravillosamente escogidos! Si el verbo, manejado con destreza, da movimiento a la prosa, el adjetivo cuando es original y exacto, le infunde gracia, color, poesía (...)» (El Diario Ilustrado de Santiago de Chile 1952).
«La cordial y calurosa manifestación de aplauso que se rindió en la Biblioteca al Dr. Porras, al terminar su disertación sobre Medina y su contribución a la historia peruana, fue expresiva del interés despertado por su interpretación de la figura de Medina como encarnación de las tendencias características de la historia chilena y de aplauso a los hallazgos documentales de su disertación (...)» (El Mercurio de Santiago de Chile 1952).

Con relación a la cobertura mediática en nuestro país que tuvo esta presentación país; esta resulta escasa, pero se puede alcanzar a mencionar un comentario periodístico del diario La Prensa (12-11-1952),

Obras de José Toribio Medina en exposición en su honor inaugurada en la Biblioteca Nacional de Chile el 1 de mayo de 1952 (colección BNCH - 1952)

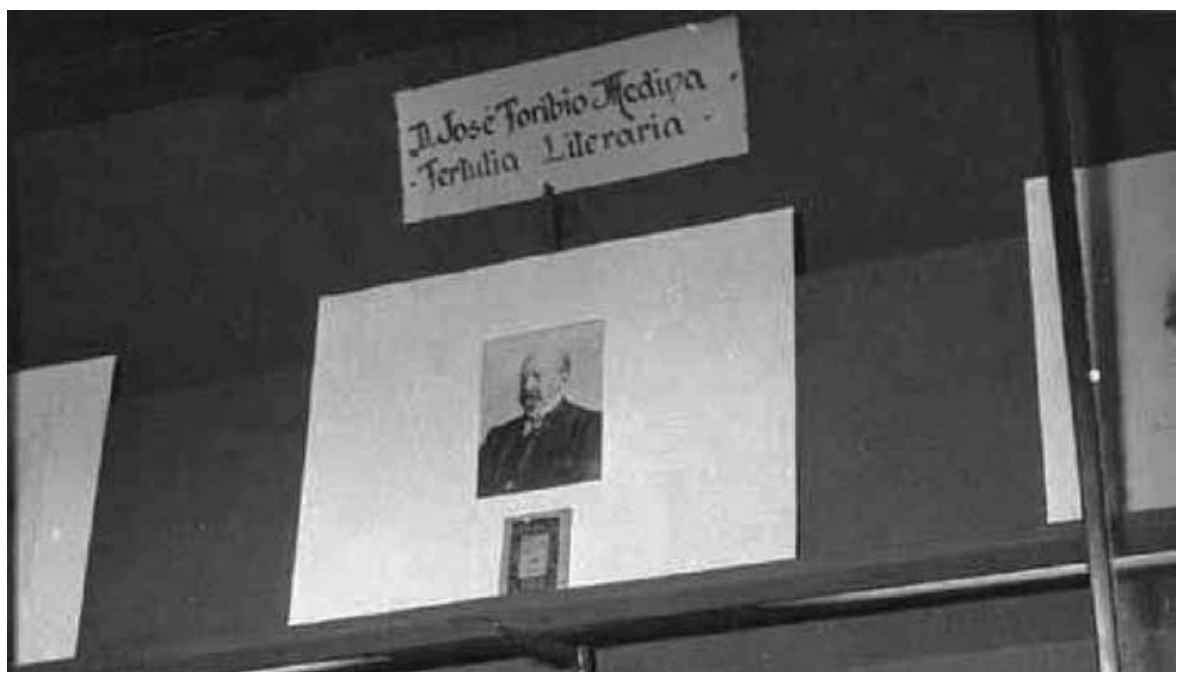




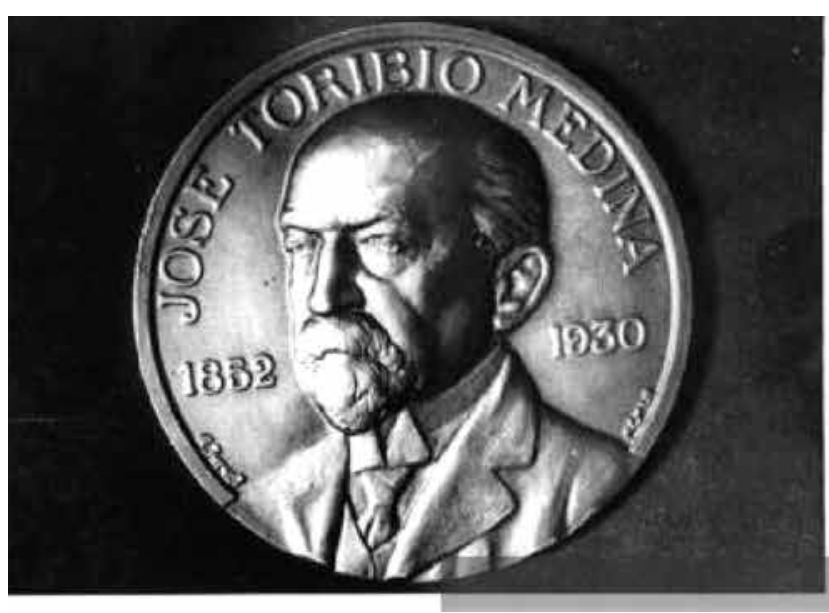

Moneda conmemorativa (colección BNCH - 1952).

una edición integra del Mercurio Peruano titulada «Homenaje a José Toribio Medina» (No 308 - Nov. 1952) y una publicación de la editorial Lumen, a modo de folleto, con el mismo contenido del Mercurio Peruano (1953). Lamentablemente, esto no hace más que reafirmar el poco interés que nuestra sociedad le otorga a sus intelectuales y a la cultura, al preferir modelos importados, en muchos casos hasta de menor cuantía.

\section{Reflexiones finales}

En suma, y a la luz de la historia, el insigne sanmarquino, Raúl Porras Barrenechea, que alguna vez refirió que «no hay patria sin historia» pues ella, la Historia, nos exige recordar hechos cuya trascendencia tuvieron un inmenso impacto sobre nuestra sociedad, tanto en el ámbito nacional e internacional como lo fue "la tragedia del 79», como él mismo dijera citando a Palma, y que sumado a la principal misión y responsabilidad social del historiador, que es la de pensar y hacer pensar. La convierten en un «actor de enseñanza cívica, de espíritu humanitario, de dignidad nacional y de desarrollo del amor a la verdad» (Porras, 1963). Esto en virtud de la relación peruana-chilena cuya tradición de compenetración y reconocimiento recíproco de nuestros préstamos culturales seculares no debe ser abandonada, porque ella es fuente segura de comprensión y amistad internacional a través del refluir de los tiempos que nos permita despertar el síndrome de una identidad y fraternidad que fue, es y será el principal baluarte para el desarrollo e integración de esta Latinoamérica; tan distinta y similar a la vez.

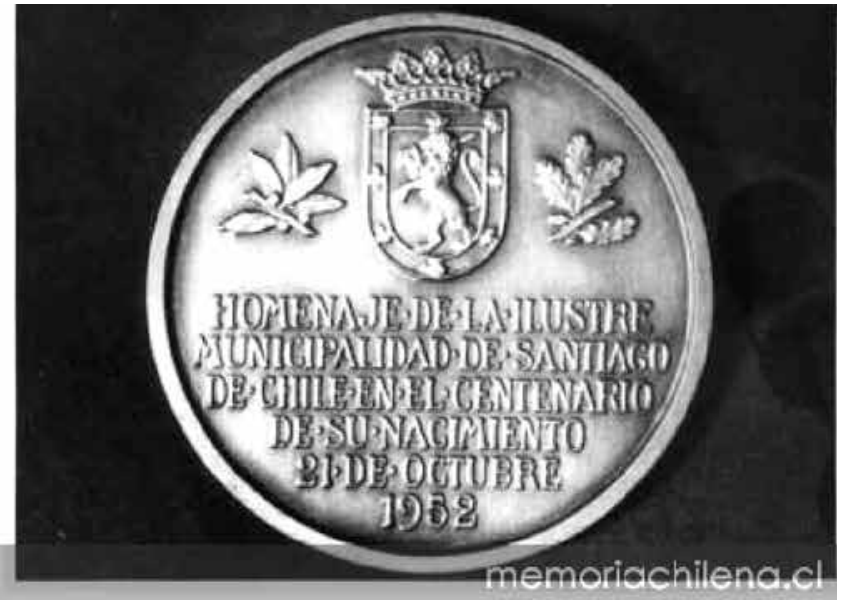

Finalmente al volver sobre las impresiones sustanciales que indujeron estas líneas, no se puede dejar de recalcar la contribución que Medina, cuyas dos últimas producciones bibliográficas u obra colofón estuvieron dedicadas al Perú como: la Bibliografía de las lenguas quechua y aimará, antes mencionada, y la reimpresión de la relación de Nicolás de Albenino sobre la revolución de Gonzalo Pizarro titulada: Verdadera relación de lo sucedido en los Reynos o Provincias del Perú desde la ida del Virrey Blasco Nuñes de Vela hasta el desbarato y muerte de Gonzalo Pizarro, realizó a la historia peruana cuyo influjo decisivo estuvo en tres campos, a decir del doctor Porras la historia de la conquista del Perú, la historia colonial y el libro y sus incursiones en la historia pre-hispánica, que resultan como vasos comunicantes que nos sirven para entender la historia, y todo de lo que de ella emana, entre ambos pueblos. En tal sentido sostuvo don Raúl:

«las culturas de Perú y Chile por su interinfluencia constante desde la época prehispánica, son inseparables, los peruanos recibimos el mensaje ilustrado de Camilo Hernández, de José Jerónimo Vivar, y de las Logias de libertad de Chile, esa tradición de compenetración y de reconocimiento recíproco de nuestros préstamos culturales, no debe ser abandonada, porque es fuente segura de comprensión y de amistad internacional» (Porras 1953).

Reflexión que se puede circunscribir al concepto de Allain Corbin que sostiene que el «individuo se hace del mundo, de un eventual más allá, de sí mismo y del otro", es decir "determina las modalidades de la observación del mundo, de la sociedad y de sí mismo» 
(Vovelle 2003:18) al encarnar la búsqueda de un entendimiento que es perfectamente aplicable para el caso del Perú y Chile a través de la vía de la conciliación histórica que además es uno de los principios y línea maestra de nuestra política internacional.

Esta manera de hacer Historia, visionaria e integradora, que permite repensar a Raúl Porras Barrenechea, lo colocan en virtud de sus afanes y trabajos en un paradigma cuyo recuerdo se hace perdurable hasta hoy a través de su obra historiográfica, la cual nos heredó al dejar un gran legado de inconmensurable valor cuyo carácter diacrónico, con el que hoy se torna, nos permite observar por la ventana del pasado, lo sincrónico de sus reflexiones sobre los diferentes problemas y posibilidades de nuestro país. La cual debe sostenerse, fundamentalmente, sobre la promoción de nuestros valores culturales con el propósito de afirmar y revalorizar nuestra identidad y, por consiguiente, valorizarnos de forma positiva y así poder competir de igual a igual con otras personas provenientes de diferentes espacios culturales motivando de esta manera la moral del ser peruano contando con la máxima posibilidad que nuestras ventajas comparativas nos ofrecen para alcanzar un desarrollo sostenible y exitoso colaborando, junto a Chile, en la inserción de nuestra región en la nueva realidad global que implica el siglo xxI y que sobre todo, ad portas de la conmemoración del Bicentenario de la proclamación de nuestra independencia, nos permita ser una nación justa y con igualdad de oportunidades.

\section{Referencias bibliográficas}

(20 de 10 de 1952). El Diario Ilustrado de Santiago de Chile. (19 de 10 de 1952). El Mercurio de Santiago de Chile.
Casalino \& Lecaros (1999). Raúl Porras Barrenechea, parlamentario. Lima: Fondo Editorial del Congreso del Perú.

Constituciones y Ordenanzas de la Universidad, y Studio general de la Ciudad de los Reyes del Piru. (1602). Ciudad de los Reyes.

CróniCa. Centenario del nacimiento de José Toribio Medina. (1952). Fénix, 364.

Letras-UNMSM, F. d. (1963). Nueva Corónica. Órganodel Dpto. de Historia. Lima: Carlos Milla Batres.

Bedoya, Puccinelli, Vargas et al. (2008). Libro de homenajes a Raúl Porras Barrenechea. Testimonios. Lima: IRPB.

Maticorena, Miguel (2000). San Marcos de Lima. Universidad Decana de América. Una argumentación histórico-jurídica . Lima: Fondo Editorial UNMSM.

Pinto-Bazurco, Ricardo (2009). Al encuentro del Bicentenario del Perú. 10.09.2017, de Historia a debate Sitio web: http://h-debate.com/bicentenario-3310/

Porras, R. (1929). José Antonio Barrenechea 1829-1889. Su vida y obra. Lima: Imp. Torres Aguirre.

Porras, Raúl. (1952). Homenaje a José Toribio Medina. Mercurio Peruano, 491-574.

Porras, Raúl. (1953). Homenaje peruano a José Toribio Medina. Lima: Lumen S.A.

Porras, Raúl. (1963). Fuentes Históricas Peruanas. Lima: IRPB.

VAlCÁrCel, Daniel. (1968). San Marcos, Universidad Decana de América. Lima: Imprenta UNMSM.

Vovelle, Michel. (2003). Aproximación a la Historia de la Mentalidades Colectivas. Lima: Fondo Editorial de la Facultad de CCSS-UNMSM.

\section{Recursos web}

www.memoriachilena.cl 